\title{
Determination of selected engineering properties of Moringa oleifera seed
}

\author{
*Abubakar, M.S. and Benjamin, I.A. \\ Department of Agricultural and Environmental Engineering, Bayero University, Kano-Nigeria
}

\section{Article history:}

Received: 6 June 2018

Received in revised form: 15

September 2018

Accepted: 8 October 2018

Available Online: 6

November 2018

\section{Keywords:}

Engineering properties,

Moringa oleifera,

Moisture content,

Seed

DOI:

https://doi.org/10.26656/fr.2017.3(2).124

\begin{abstract}
Engineering properties of agricultural products are very important in the design and manufacturing of processing machines. The methods adopted in the study were standard laboratory procedures for the determination of the engineering properties selected. In this research, the dimensional, gravimetric and frictional properties of Moringa oleifera seeds were determined as design parameters for the development of post-harvest equipment. The selected properties were: length, width, thickness, arithmetic and geometric diameters, surface areas, sphericity, moisture content, bulk and true densities, porosity, one thousand and unit seed weights, angle of repose and coefficient of static friction. The moisture contents used in the study were $7.82 \%$ and $15.82 \%$ dry basis $(\mathrm{db})$. The mean seed length of $9.217 \pm 1.407 \mathrm{~mm}$, width of $8.012 \pm 1.349 \mathrm{~mm}$ and thickness of $5.443 \pm 1.382 \mathrm{~mm}$ was found at moisture contents of $7.82 \%(\mathrm{db})$ respectively. While the mean seed length of $11.460 \pm 1.106 \mathrm{~mm}$, width of $10.079 \pm 1.065 \mathrm{~mm}$ and thickness of $7.377 \pm 1.079 \mathrm{~mm}$ were obtained at moisture content of $15.82 \%(\mathrm{db})$ respectively. The mean arithmetic diameter, geometric mean diameter, sphericity and surface area at moisture content of $7.82 \%(\mathrm{db})$ were $7.557 \pm 1.3407 \mathrm{~mm}, 7.366 \pm 1.374 \mathrm{~mm}, 0.7964 \pm 0.048 \mathrm{~mm}, 176.185 \pm 64.416 \mathrm{~mm}^{2}$ respectively. Also, the mean arithmetic diameter, geometric mean diameter, sphericity and surface area at moisture content of $15.82 \%(\mathrm{db})$ were $9.639 \pm 1.049 \mathrm{~mm}, 9.475 \pm 1.065 \mathrm{~mm}$, $0.826 \pm 0.030 \mathrm{~mm}, 285.476 \pm 65.753 \mathrm{~mm}^{2}$ respectively. The mean true density, bulk density, average porosity, unit mass and thousand seed mass at $7.82 \%(\mathrm{db})$ moisture content were found to be $0.5100 \pm 0.025 \mathrm{gcm}^{-3}, 0.247 \pm 0.0580 \mathrm{gcm}^{3} ; 58.86 \%, 0.339 \pm 0.061 \mathrm{~g}$, and $272.051 \pm 11.827 \mathrm{~g}$ respectively. Also, the average true density, bulk density, average porosity, unit mass and thousand seed mass at $15.82 \%(\mathrm{db})$ moisture content were $0.610 \pm 0.030 \mathrm{gcm}^{-3}, 0.253 \pm 0.005 \mathrm{gcm}^{-3}, 58.52 \%, 0.350 \pm 0.055 \mathrm{~g}$, and $273.396 \pm 8.079 \mathrm{~g}$ respectively. The mean angle of repose, average static coefficient of friction on three different surfaces that include: glass, galvanized steel, and plywood at $7.82 \%(\mathrm{db})$ moisture content was found to be $17.834 \pm 0.350^{\circ}, 0.437 \pm 0.003,0.481 \pm 0.002$, and $0.569 \pm 0.003$ respectively. Also, the mean angle of repose, average static coefficient of friction on three different surfaces that include: glass, galvanized steel, and plywood at $15.82 \%(\mathrm{db})$ moisture content were found to be $19.345 \pm 0.409^{\circ}, 0.471 \pm 0.002$, $0.570 \pm 0.002$, and $0.612 \pm 0.013$ respectively. These parameters would serve as inputs for the efficient design of post-harvest equipment for M. oleifera seeds.
\end{abstract}

\section{Introduction}

Moringa oleifera is native to some parts of Africa and Asia and it is the sole genus in the flowering plant family Moringaceae (Zaku et al., 2015). M. oleifera has been in use for many centuries in traditional alternative medicine to heal or prevent hundreds of diseases (Aremu and Akintola, 2014), and because of its numerous healing and nutritional properties, it is called "Miracle Tree", "Mother's Best Friend" and "Never Die". The other common names of $M$. oleifera include "horseradish tree" and "drumstick tree". The history of M. oleifera according to Zaku et al. (2015) dates back to 150 B.C when ancient kings and queens used $M$. oleifera leaves and fruit in their diet to maintain mental alertness and healthy skin. A mature $M$. oleifera grows up to a height of 6-7 $\mathrm{m}$ and is a drought-resistant and fast growing plant (Ramachandran et al., 1980; Fuglie, 1999). There are thirteen varieties of moringa trees in the family, according to Aremu and Akintola (2014) which includes: 
M. stenopetala, M. doughardii. M. arborea, M. borziana, M. longituba, M. rivae, M. pygmaea, M. ruspoliana, $M$. hildebrandtii, $M$. ovalifolia, $M$. concanensis, $M$. oleifera and $M$. peregrina. However, M. oleifera is the most widely known variety. It is also a readily available diet used to help prevent malnutrition in children, pregnant women and nursing mothers (Ndubuaku et al., 2014). The leaves and seeds have been found to be highly nutritious and medicinal. The seeds yield edible oil that is clear and odorless. It burns without smoke and will not turn rancid. The seeds are $35 \%$ oil and the remaining seed cake can be used as fertilizer or to purify water (Abdullah et al., 2013). M. oleifera seeds contain a significant amount of oil that is commercially known as "Ben oil" or "Behen oil" due to the fact that oil contains high amounts of behenic acid which is used in many products for its ability to smooth the skin and condition hair. It could also be used in cooking, cosmetics, fuel and lubrication among others.

The characteristics of $M$. oleifera seed oil can be highly desirable especially with the current trend of replacing polyunsaturated vegetable oils with those containing high amounts of monounsaturated acids (Corbett, 2003). In recent times, increased attention has been focused on the utilization of under-exploited locally available agricultural products and by-products for food/ fibre processing in developing countries. Obviously, such utilization would help these countries, especially African countries that are currently facing adverse economic problems. Due to the facts that $M$. oleifera is harvested and collected manually by handpicking, there are always unwanted materials in all the harvested seeds which necessitates the need for the cleaning of the seeds. For further processing of the harvested seeds, there is a need for the determination of engineering properties, such as physical, chemical and oil properties among others. The knowledge of these properties is highly relevant to agricultural engineers due to the increasing economic importance of food materials, together with the complexity of modern technology for their production, handling, storage, processing, preservation, value addition and utilization (Adebayo and Nwankwo, 2013).

A rational approach to the design of agricultural machinery, equipment and facilities involve the knowledge of the properties of the agricultural product concerned. The need for comprehensive information on its properties is of importance, as these properties influence the design and evaluation of the processing/ handling of the product. Considering this, the knowledge of the engineering properties of agricultural seed materials are important in designing the equipment for harvest, transport, storage, processing, cleaning, hulling and milling (Niveditha et al., 2013). Also Adejumo and
Abayomi (2012) conducted a study on the effect of moisture content on some physical properties of shelled and unshelled $M$. oleifera seed at $6.8 \%, 10 \%, 15 \%$ moisture content (wet basis) and obtained the following results: the mean values of the physical properties of the seeds were determined as length $8.3-8.7 \mathrm{~mm}$ and 12.7$13.4 \mathrm{~mm}$, width 7.4-7.6 $\mathrm{mm}$ and $10.3-11.0 \mathrm{~mm}$, thickness $6.5-7.3 \mathrm{~mm}$ and 10.4-10.9 mm, geometric mean diameter $133.1-160.1 \mathrm{~mm}$ and $453.5-535.6 \mathrm{~mm}$, sphericity $16.0-18.4 \mathrm{~mm}$ and $35.7-40.0 \mathrm{~mm}$, thousand seed mass 316.8-326.7 $\mathrm{g}$ and 318.3-329.3 g, bulk density $0.031-0.032 \mathrm{~g} / \mathrm{cm}$ and $0.041-0.047 \mathrm{~g} / \mathrm{cm}^{3}$, true density $0.221-0.632 \mathrm{~g} / \mathrm{cm}^{3}$ and $0.300-0.289 \mathrm{~g} / \mathrm{cm}^{3}$, porosity 85.9 $94.9 \%$ and $86.3-83.7 \%$, surface area $3.19-2.21 \mathrm{~cm}^{3}$ and 3.56-5.32 $\mathrm{cm}^{3}$ for shelled and unshelled seeds respectively. Also, Oloyede et al. (2015) measured some engineering properties necessary to design drumstick $M$. oleifera L. pod sheller. The basic dimensions (length, width, and thickness) of moringa pods and seeds were found to increase linearly from 311.15 to $371.45 \mathrm{~mm}$, 22.79 to $31.22 \mathrm{~mm}$, and 22.24 to $29.88 \mathrm{~mm}$, respectively, in the moisture range of 12 to $49.5 \% \mathrm{db}$. The coefficient of friction for both pods and seeds increased linearly with an increase in moisture content on all the surfaces used. The highest value was recorded on mild steel, with 0.581 for pods and 0.3533 for seeds, and the lowest on glass for pods, with a value of 0.501 , and of 0.2933 for seeds on galvanized steel. These properties influence the design and evaluation of the processing of the seed. In this research, the dimensional, gravimetric and frictional properties of $M$. oleifera seeds were determined and presented as design parameters for the development of post-harvest equipment.

\section{Materials and methods}

\subsection{Sample preparation}

The dry seeds of $M$. oleifera were obtained from Kano station of Forestry Research Institute of Nigeria (FRIN) and used for all the experiments in the study. The seeds were cleaned manually to remove all foreign matter such as dirt, stones and chaff as well as immature and broken seeds. It was then sealed and kept in a polyethylene bag for $78 \mathrm{hrs}$ to equilibrate the moisture content of the seed. Seed samples were randomly taken to determine the initial moisture content by drying in an air ventilated oven at $103^{\circ} \mathrm{C}$ for $24 \mathrm{hrs}$ (Ahmadi, 2009) and the average values obtained was recorded.

The remaining seed mass was divided into two sets. One set of the seed samples was reconstituted in addition to the initial moisture content of the sample by adding a calculated amount of distilled water and sealed in a polyethylene bag and stored in a refrigerator at $5^{\circ} \mathrm{C}$ for five days to enable the moisture to distribute uniformly 
throughout the seed sample (Ahmadi, 2009). The amount of water added to the sample in order to achieve the desired moisture was calculated using equation (1) as given by Solomon and Zewdu (2009):

$$
\mathrm{Q}=\frac{\mathrm{W}_{\mathrm{s}}\left(\mathrm{M}_{\mathrm{f}}-\mathrm{M}_{\mathrm{i}}\right)}{100-\mathrm{M}_{\mathrm{f}}}
$$

Where $\mathrm{Q}=$ Quantity of water to be added, $\mathrm{g} ; \mathrm{M}_{\mathrm{i}}=$ initial moisture content; $\%, \mathrm{M}_{\mathrm{f}}=$ required moisture content; $\%$, $\mathrm{W}_{\mathrm{s}}=$ weight of samples, $\mathrm{g}$.

Before starting a test, the required quantity of the seed was taken out of the refrigerator and allowed to equilibrate to the room temperature for about $2 \mathrm{hrs}$ (Singh and Goswami, 1996) and after which the reconstituted samples were checked for the moisture content using the method described by Adesina et al. (2014). All analysis was carried out in the Department of Agricultural and Environmental Engineering's Laboratory, Faculty of Engineering Bayero University, Kano, Nigeria.

\subsection{Determination of moisture content}

The initial moisture content dry basis of the seed samples was determined using the relationship obtained from Adesina et al. (2014)

$$
\mathrm{M}_{\mathrm{db}}=\left(\frac{\mathrm{W}_{\mathrm{i}}-\mathrm{W}_{\mathrm{f}}}{\mathrm{W}_{\mathrm{f}}}\right) \times 100
$$

Where $\mathrm{M}_{\mathrm{db}}=$ dry basis moisture content; $\mathrm{W}_{\mathrm{i}}=$ initial weight of the seeds in grams; $\mathrm{W}_{\mathrm{f}}=$ final weight of the seeds in grams

\subsection{Dimensional measurement}

The physical dimensions of the seed were determined by taking 25 seeds randomly and measured the length, width and thickness at the different moisture contents using a micrometer screw gauge (with $0.01 \mathrm{~mm}$ accuracy and 0-25 mm main reading (Model GMC- 20). The seed length was defined as the longest dimension. Width is the longest dimension perpendicular to length. Thickness is the longest dimension perpendicular to the length by width plane Adesina et al. (2014) (Figure 1).

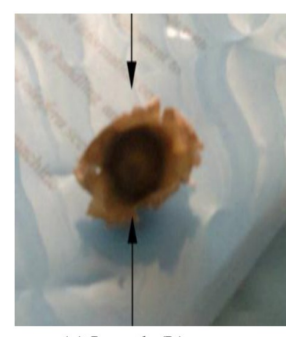

(a) Length (L)

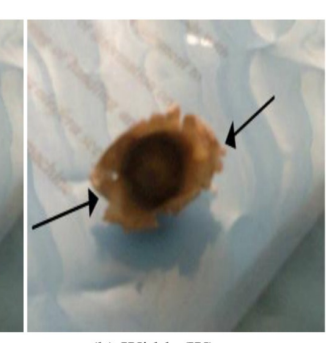

(b) Width (W)

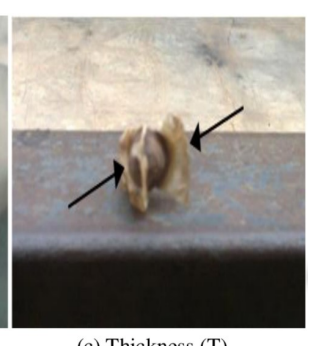

(c) Thickness (T)
Figure 1. Measurement of dimensional axes

The arithmetic mean diameter, and geometric mean diameter was calculated using equation (3) and (4) respectively as used by Adesina et al. (2014):

$$
\begin{aligned}
& D a=\frac{\mathrm{T} \pm \mathrm{W} \pm \mathrm{L}}{3} \\
& D g=(\mathrm{LWT})^{\frac{1}{3}}
\end{aligned}
$$

Where $\mathrm{L}$ is the length in mm; $\mathrm{W}$ is the width in $\mathrm{mm}$; $\mathrm{T}$ is the thickness in mm; $D a$ and $D g$ are arithmetic and geometric mean diameters, respectively

\subsubsection{Determination of sphericity $(\varphi)$}

Sphericity was obtained using the equation (5) below as given by Adesina et al. (2014)

$\varphi=\frac{(\mathrm{LWT})^{\frac{1}{3}}}{\mathrm{~L}}$

Where $\varphi=$ Sphericity; $\mathrm{L}$ is the length in $\mathrm{mm}$; $\mathrm{W}$ is the width in $\mathrm{mm}$; and $\mathrm{T}$ is the thickness in $\mathrm{mm}$.

\subsubsection{Determination of surface area $(S)$}

The surface area, (S) in $\mathrm{mm}^{2}$ was calculated by using equation (6) below as given by Niveditha et al. (2013).

$$
\mathrm{S}=\pi \mathrm{D}_{\mathrm{g}}{ }^{2}
$$

Where; $\mathrm{S}=$ surface area; and $\mathrm{Dg}=$ geometric mean diameter.

\subsection{Gravimetric Measurement}

\subsubsection{Determination of unit and one thousand seed mass}

Mass of 1000 seeds of M. oleifera was determined by counting 100 seeds randomly and measured using an electrical digital balance (Model MP1001, gallen kamp) with maximum capacity of $600 \mathrm{~g}$ and accuracy $0.01 \mathrm{~g}$ and then was multiplied by 10 to give the mass of 1000 seeds and divided by 100 to give the unit mass (Adesina et al., 2014). The test was done in ten replicates and mean value was taken.

\subsubsection{Determination of solid density}

The true or solid density can be defined as the ratio of a given mass of sample to its volume and was determined by using water displacement method. The solid density was calculated using equation (7) below as given by Adesina et al. (2014). The test was done in ten replicates and the mean value was taken:

$$
\text { True density }(\mathrm{g} / \mathrm{cm} 3)=\frac{\text { weight of the sample }(\mathrm{g})}{\text { Volume of distilled water displaced }\left(\mathrm{cm}^{3}\right)}
$$

\subsubsection{Determination of bulk density}

Bulk density was determined by weighing the grains packed in a container of known volume. The equation (8) below as given by Aviara et al. (2017) was used to determine the bulk density of the grain sample. 


$$
\rho_{\mathrm{b}}=\frac{\mathrm{M}_{\mathrm{b}}}{\mathrm{V}_{\mathrm{b}}}
$$

Where $\rho_{b}=$ Bulk density of the seeds $\left(\mathrm{g} / \mathrm{cm}^{3}\right) ; M_{b}=$ mass of seeds in the beaker $(\mathrm{g})$; and $\mathrm{V}_{\mathrm{b}}=$ volume of beaker $\left(\mathrm{cm}^{3}\right)$.

\subsubsection{Determination of porosity}

The porosity of the seeds was calculated using equation (9) as utilized by Aviara et al. (2017).

$$
\text { Porosity }=\left(1-\frac{\rho_{\mathrm{b}}}{\rho_{\mathrm{s}}} \times 100\right)
$$

Where $\rho_{b}=$ bulk density $\left(\mathrm{g} / \mathrm{cm}^{3}\right)$; and $=\rho_{s}$ solid density $\left(\mathrm{g} / \mathrm{cm}^{3}\right)$.

\subsection{Frictional properties}

\subsubsection{Determination of Angle of repose}

The angle of repose of the $M$. oleifera seeds was determined using the cylindrical pipe method. A topless and bottomless cylinder was filled with grains and slowly raised on a surface until it leaves the seeds forming a cone, and the radius of the base and height of the cone that was formed by the grains were used to calculate the angle of repose. Equation (10) below was used to determine the angle of repose as given by Zewdu and Solomon (2007). The test was done in ten replicates and mean value was taken.

$$
\theta=\tan ^{-1}\left(\frac{h}{r}\right)
$$

Where $\Theta=$ angle of repose $\left({ }^{\circ}\right) ; \mathrm{h}=$ height of piled seed $(\mathrm{cm})$; and $\mathrm{r}=$ radius of base of cone $(\mathrm{cm})$

\subsubsection{Determination of coefficient of static friction}

Coefficient of static friction $(\mu)$ was determined on three different surfaces (plywood, galvanized steel and glass), which are commonly used for the construction of processing and handling machine (Niveditha et al., 2013). A plastic cylinder of $100 \mathrm{~mm}$, diameter and 50 $\mathrm{mm}$ height as described by Adesina et al. (2014) was used. The cylinder was filled with seed and placed on an adjustable inclined surface. The plastic cylinder was raised slightly so that its open bottom edge did not touch the inclined surface only the seed samples were touching the surface. All three surfaces were raised slowly until the cylinder filled with seeds started to slide down. At that point, the angle of tilt, $(\theta)$ was recorded. Coefficient of static friction $(\mu)$ was calculated using the equation (11) below. The test was done in ten replicates and mean value was taken.

$$
\mu=\tan \theta
$$

\section{Results and discussion}

The results obtained were subjected to statistical analysis using Microsoft Excel 2007 (Microsoft Corp., USA). Tukey's test at a significance level of $p<0.05$ was used to compare means of all the parameters calculated at the initial moisture content of $7.82 \%(\mathrm{db})$ to that measured at $8 \%$ increase in moisture content of $15.82 \%$ $(d b)$.

\subsection{Seed axial dimensional}

The results of $M$. oleifera seed axial dimensions obtained at two different moisture content levels are presented in Table 1. The Table shows that the three axial dimensions of the seed increased with moisture content in the moisture of $7.82 \%$ and $15.82 \%(\mathrm{db}$.), the major axis (length) increased from $(9.217 \pm 1.407) \mathrm{mm}$ to $(11.460 \pm 1.106) \mathrm{mm}$, the intermediate axis (width) from $(8.012 \pm 1.349) \mathrm{mm}$ to $(10.078 \pm 1.065) \mathrm{mm}$, and the minor axis (thickness) from $(5.443 \pm 1.382) \mathrm{mm}$ to $(7.377 \pm 1.079) \mathrm{mm}$. This was in agreement with the work

Table 1. Statistical value of the measured and calculated axial dimensional of the M. oleifera seed

\begin{tabular}{lccccccc}
\hline \multirow{2}{*}{ Parameters and Unit } & $\begin{array}{c}\text { Moisture } \\
\text { content }(\mathrm{db})\end{array}$ & $\mathrm{N}$ & \multirow{2}{*}{ Mean \pm SD } & Std. Err. & t-value & \multicolumn{2}{c}{ 95\% Conf. Interval } \\
\hline \multirow{2}{*}{ Length $(\mathrm{mm})$} & $7.82 \%$ & 25 & $9.217 \pm 1.407$ & 0.281 & -6.268 & 8.636 & 9.798 \\
& $15.82 \%$ & 25 & $11.460 \pm 1.106$ & 0.221 & -6.268 & 11.003 & 11.916 \\
\hline \multirow{2}{*}{ Width $(\mathrm{mm})$} & $7.82 \%$ & 25 & $8.012 \pm 1.349$ & 0.270 & -6.012 & 7.456 & 8.569 \\
& $15.82 \%$ & 25 & $10.079 \pm 1.065$ & 0.213 & -6.012 & 9.639 & 10.518 \\
\hline \multirow{2}{*}{ Thickness $(\mathrm{mm})$} & $7.82 \%$ & 25 & $5.443 \pm 1.382$ & 0.276 & -5.517 & 4.872 & 6.013 \\
& $15.82 \%$ & 25 & $7.377 \pm 1.079$ & 0.216 & -5.517 & 6.932 & 7.823 \\
\hline \multirow{2}{*}{ Arithmetic diameter $(\mathrm{mm})$} & $7.82 \%$ & 25 & $7.557 \pm 1.3407$ & 0.268 & -6.117 & 7.004 & 8.110 \\
& $15.82 \%$ & 25 & $9.639 \pm 1.409$ & 0.210 & -6.117 & 9.206 & 10.071 \\
\hline \multirow{2}{*}{ Geometric diameter $(\mathrm{mm})$} & $7.82 \%$ & 25 & $7.366 \pm 1.374$ & 0.275 & -6.064 & 6.799 & 7.933 \\
& $15.82 \%$ & 25 & $9.475 \pm 1.065$ & 0.213 & -6.064 & 9.035 & 9.914 \\
\hline \multirow{2}{*}{ Sphericity $(\mathrm{mm})$} & $7.82 \%$ & 25 & $0.7964 \pm 0.048$ & 0.010 & -2.611 & 0.777 & 0.816 \\
& $15.82 \%$ & 25 & $0.836 \pm 0.030$ & 0.006 & -2.611 & 0.814 & 0.839 \\
\hline \multirow{2}{*}{ Surface area $\left(\mathrm{mm}^{2}\right)$} & $7.82 \%$ & 25 & $176.185 \pm 64.416$ & 12.883 & -5.937 & 149.596 & 202.775 \\
& $15.82 \%$ & 25 & $285.476 \pm 65.753$ & 13.151 & -5.937 & 258.335 & 312.617 \\
\hline
\end{tabular}


of Aja and Fakoyode (2013), who measured some engineering properties of $M$. oleifera and found to have increased of $8.45 \pm 0.976 \mathrm{~mm}, 7.82 \pm 0.922 \mathrm{~mm}$ and $6.41 \pm 1.092 \mathrm{~mm}$ respectively. The increasing trend in axial dimensions, this gained in moisture content, might be due to the filling of voids upon absorption of moisture and subsequent swelling. The arithmetic mean diameter had higher mean values of $(7.557 \pm 1.340 \mathrm{~mm}$ to $9.639 \pm 1.049 \mathrm{~mm})$ than the geometric $(7.366 \pm 1.374) \mathrm{mm}$ to $(9.475 \pm 1.065) \mathrm{mm}$, sphericity $(0.796 \pm 0.048 \mathrm{~mm}$ to $0.826 \pm 0.0302 \mathrm{~mm})$ and the surface area $\left(176.185 \pm 64.416 \mathrm{~mm}^{2}\right.$ to $\left.285.476 \pm 65.753 \mathrm{~mm}^{2}\right)$ of the seed. These could be of important consideration in the theoretical determination of the $M$. oleifera seed volume at different moisture contents. Moreover, assessment of the mean geometric diameter is useful in the evaluation of the projected area of a particle moving in the turbulent or near-turbulent area of an air stream.

The null hypothesis was tested on the assumption that seeds exposed to $7.82 \%$ and $15.82 \%$ moisture contents have the same effect on the dimensional properties of the seed, i.e. the difference in the means of the treatments (moisture content) is zero. This indicates that the null hypothesis was rejected out-rightly and means that there was a significant difference between the means of the axial dimension at $5 \%$ level of significance.

\subsection{Seed gravimetric properties}

The mean true and bulk densities were found to be $0.600 \pm 0.025 \mathrm{gcm}^{-3}, 0.247 \pm 006 \mathrm{gcm}^{-3}$ and $0.610 \pm 030$ $\mathrm{gcm}^{-3}$ and $0.253 \pm 0.005 \mathrm{gcm}^{-3}$ at $7.82 \%$ and $15.82 \%$ moisture levels respectively. The porosity was computed from the values of the true and bulk densities as $58.86 \%$ and $58.52 \%$ at $7.82 \%$ and $15.82 \%$ moisture contents respectively. The true density of the $M$. oleifera seeds shows that the seeds were slightly less dense than water $\left(1.00 \mathrm{~g} / \mathrm{cm}^{3}\right)$ and therefore will float on water. It was noticed also that all the gravimetric properties increased with increase in moisture content (Table 2). The unit mass increased from $0.339 \pm 0.061 \mathrm{~g} / \mathrm{cm}^{3}$ at $7.82 \%$ moisture content to $0.350 \pm 0.055 \mathrm{~g} / \mathrm{cm}^{3}$ at $15.82 \%$ moisture content. The 1000 seeds mass also increased from $272.051 \pm 11.827 \mathrm{gcm}^{-3}$ at $7.82 \%$ moisture content to $273.396 \pm 8.079 \mathrm{gcm}^{-3}$. Based on the gravimetric analysis of the seed, result shown that the different moisture contents $(7.8 \%$ and $15.82 \%)$ have the same effect on the true density, unit mass and thousand seed weight of the seed, except the bulk density of the seed in which there was a significant difference in their mean effects.

\subsection{Frictional properties of M. oleifera seed}

The average coefficients of friction on three different surfaces viz glass, galvanized steel and plywood were found to be $0.437 \pm 0.003,0.481 \pm 0.002$ and $0.569 \pm 0.003$ respectively at $7.82 \%$ moisture content (Table 3 ). The average values for glass, galvanized steel and plywood at $15.82 \%$ moisture content was found to increase to $0.470 \pm 0.002, \quad 0.570 \pm 0.002$ and $0.612 \pm 0.013$. It was observed that the static coefficient of friction was highest on plywood and lowest on glass. The mean angle of repose was found to be $17.834 \pm 0.351^{\circ}$ at $7.82 \%$ moisture content and $19.345 \pm 0.409^{0}$ at $15.82 \%$ moisture content.

Table 2. Statistical values of the measured and calculated gravitational properties of the $M$. oleifera seed

\begin{tabular}{lccccccc}
\hline \multirow{2}{*}{ Parameters and Unit } & $\begin{array}{c}\text { Moisture } \\
\text { content }(\mathrm{db})\end{array}$ & $\mathrm{N}$ & \multirow{2}{*}{ Mean \pm SD } & \multirow{2}{*}{ Std. Err. } & t-value & \multicolumn{2}{c}{ 95\% Conf. Interval } \\
\cline { 4 - 8 } True density $\left(\mathrm{g} / \mathrm{cm}^{3}\right)$ & $7.82 \%$ & 10 & $0.510 \pm 0.025$ & 0.008 & -0.812 & 0.582 & 0.618 \\
& $15.82 \%$ & 10 & $0.610 \pm 0.030$ & 0.009 & -0.812 & 0.589 & 0.631 \\
\hline \multirow{2}{*}{ Bulk density $\left(\mathrm{g} / \mathrm{cm}^{3}\right)$} & $7.82 \%$ & 10 & $0.247 \pm 0.058$ & 0.002 & -2.506 & 0.243 & 0.251 \\
& $15.82 \%$ & 10 & $0.253 \pm 0.005$ & 0.002 & -2.506 & 0.249 & 0.257 \\
\hline \multirow{2}{*}{ Unit mass $(\mathrm{g})$} & $7.82 \%$ & 10 & $0.339 \pm 0.061$ & 0.0019 & -0.400 & 0.296 & 0.383 \\
& $15.82 \%$ & 10 & $0.350 \pm 0.055$ & 0.017 & -0.400 & 0.310 & 0.389 \\
\hline \multirow{2}{*}{ Thousand seed mass $(\mathrm{g})$} & $7.82 \%$ & 10 & $272.051 \pm 11.827$ & 3.740 & -0.297 & 263.590 & 280.512 \\
& $15.82 \%$ & 10 & $273.396 \pm 8.079$ & 2.555 & -0.297 & 267.617 & 279.175 \\
\hline
\end{tabular}

Table 3. Statistical values of the measured and calculated frictional properties of the M. oleifera seed

\begin{tabular}{lccccccc}
\hline \multirow{2}{*}{ Parameters and Unit } & $\begin{array}{c}\text { Moisture } \\
\text { content }(\mathrm{db})\end{array}$ & $\mathrm{N}$ & \multirow{2}{*}{ Mean \pm SD } & \multirow{2}{*}{ Std. Err. } & \multirow{2}{*}{ t-value } & \multicolumn{2}{c}{ 95\% Conf. Interval } \\
\cline { 5 - 8 } Coefficient of static friction on glass & $7.82 \%$ & 1 & $0.437 \pm 0.003$ & 0.000867 & -34.589 & 0.435 & 0.439 \\
& $15.82 \%$ & 0 & $0.471 \pm 0.002$ & 0.000482 & -34.589 & 0.470 & 0.472 \\
\hline Coefficient of static friction on & $7.82 \%$ & 1 & $0.481 \pm 0.002$ & 0.000593 & -104.050 & 0.480 & 0.482 \\
galvanized steel & $15.82 \%$ & 0 & $0.570 \pm 0.002$ & 0.000616 & -104.050 & 0.568 & 0.571 \\
\hline Coefficient of static friction on & $7.82 \%$ & 1 & $0.569 \pm 0.003$ & 0.000971 & -9.989 & 0.567 & 0.571 \\
plywood & $15.82 \%$ & 0 & $0.612 \pm 0.013$ & 0.004142 & -9.989 & 0.602 & 0.620 \\
\hline \multirow{2}{*}{ Angle of repose } & $7.82 \%$ & 1 & $17.834 \pm 0.351$ & 0.110857 & -8.871 & 17.785 & 18.085 \\
& $15.82 \%$ & 0 & $19.345 \pm 0.409$ & 0.129300 & -8.871 & 19.053 & 19.638 \\
\hline
\end{tabular}




\section{Conclusion}

The determination of selected engineering properties of M. oleifera seeds at two moisture content $7.82 \%(\mathrm{db})$ and $15.82 \%(\mathrm{db})$ show that the higher the moisture content present in the seed the higher the value of its length, width and thickness. This study also shows that a significant change in the moisture content will also lead to a significant change in the physical properties of the seed.

\section{References}

Abdullah, B.M., Yusop, R.M., Salimon, J., Jousif, E., Salih, N., Abiodun, O.A. and Prince, M.L. (2013). Oil potential of Moringa. Agrosearch, 12(2), 68-69.

Adebayo, S.E. and Nwankwo, C.C. (2013). Determination of Some Engineering Properties of Dika Nut (Irvangia gabonesis) at Two Moisture Content Levels as Relevant to its Processing. International Journal of Engineering Research and Applications, 3(2), 182-188.

Adejumo, B.O. and Abayomi, D.A. (2012). Effect of Moisture Content on some Physical Properties of Moringa oleifera Seed. IOSR Journal of Agriculture and Veterinary Science, 1(5), 12-21. https:// doi.org/10.9790/2380-0151221

Adesina, B.S., Asiru, W.B., Omotade, S.A., Diabana, P.D. and Akinyemi, D. (2014). Some Mechanical Properties of Moringa oleifera seeds. International Journal of Scientific and Engineering Research, 5 (6), 1286-1295.

Ahmadi, H. (2009). Some Physical and Mechanical Properties of Fennel Seed (Foeniculum vulgare). Journal of Agricultural Science, 1(1), 66-75.

Aja, E.A. and Fakoyode, O.A. (2013). Mechanical Properties of Moringa (Moringa oleifera) Seeds in relation to an Oil Expeller Design. Agrosearch, 13 (3), 206-216.

Aremu, A.K. and Akintola, A. (2014). Effects of Some Drying Methods on Nutritional Characteristics of Moringa (Moringa oleifera) seeds. In $4^{\text {th }}$ International Conference on Biotechnology and Environment Management, Vol. 75, p. 66-72. Singapore: IPCBEE.

Aviara N.A., Kawuyo, U.A. and Okolo, D.C. (2017). Physical Properties of Two Acha Varieties as a Function of Moisture Content. Arid Zone Journal of Engineering, Technology and Environment, 13(5), 555-566.

Corbett, P. (2003). It is time for an oil change! Opportunities for high oleic vegetable oils. Inform, 14(8), 480-481.
Oloyede. D.O., Aviara, N.A. and Shittu, S.K. (2015). Measurement of Engineering Properties Necessary to the Design of Drumstick (Moringa oleifera L.) Pod Sheller. Journal of Biosystems Engineering, 40 (3), 201-211. https://doi.org/10.5307/ JBE.2015.40.3.201

Fuglie L.J. (1999). The Miracle Tree. Moringa Oleifera. Natural Nutrition for the Tropics, p. 66. Dakar: Church World Service.

Ndubuaku, U.M., Ndubuaku, T.C.N. and Ndubuaku, N.E. (2014). Yield Characteristics of Moringa oleifera Across Different Ecologies in Nigeria as an Index of its Adaptation to Climate Change. Sustainable Agriculture Research, 3(1), 22-25.

Niveditha, V.R., Sridhar, K.R. and Balasubramanian, D. (2013). Physical and mechanical properties of seeds and kernels of Canavalia of coastal sand dunes. International Food Research Journal, 20(4), 1547 1554.

Ramachandran. C., Peter, K.V. and Gopalakrishnan, P.K. (1980). Drumstick (Moringa oleifera): A multipurpose Indian Vegetable. Economic Botany, 34(3), 276-283. https://doi.org/10.1007/BF02858648

Singh, K.K. and Goswami, T.K. (1996). Physical properties of cumin seed. Journal of Agricultural Engineering Research, 64, 93-98. https:// doi.org/10.1006/jaer.1996.0049

Solomon, W.K. and Zewdu, A.D. (2009). Moisture Dependent Physical Properties of Niger (Guiconia abyssinica Cass.) Seed. Industrial Crops and Products, 2(9), 165-170. https://doi.org/10.1016/ j.indcrop.2008.04.018

Zaku, S.G., Emmanuel, S., Tukur, A.A. and Kabir, A. (2015). Moringa oleifera: An underutilized tree in Nigeria with amazing versatility: A review. African Journal of Food Science, 9(9), 456-461. https:// doi.org/10.5897/AJFS2015.1346

Zewdu, A.D. and Solomon, W.K. (2007). Moisturedependent physical properties of Tef seed. Biosystems Engineering, 96(1), 57-63. https:// doi.org/10.1016/j.biosystemseng.2006.09.008 